\title{
Inflation and Taxes in a Growing Economy with Debt and Equity Finance
}

\section{Citation}

Feldstein, Martin, Jerry Green, and Eytan Sheshinski. 1978. Inflation and taxes in a growing economy with debt and equity finance. Journal of Political Economy 86, no. S2: S53-S70.

\section{Published Version}

http://dx.doi.org/10.1086/260694

\section{Permanent link}

http://nrs.harvard.edu/urn-3:HUL.InstRepos:3203645

\section{Terms of Use}

This article was downloaded from Harvard University's DASH repository, and is made available under the terms and conditions applicable to Other Posted Material, as set forth at http:// nrs.harvard.edu/urn-3:HUL.InstRepos:dash.current.terms-of-use\#LAA

\section{Share Your Story}

The Harvard community has made this article openly available.

Please share how this access benefits you. Submit a story.

Accessibility 


\title{
Inflation and Taxes in a Growing Economy with Debt and Equity Finance
}

\section{Martin Feldstein and Jerry Green}

\author{
Harvard University
}

\section{Eytan Sheshinski}

Hebrew University of Jerusalem

With Appendix by Alan Auerbach

Our tax system was designed for an economy with little or no inflation. The current paper shows that inflation causes capricious changes in the effective rate of tax on capital income and therefore in the real net rate of return that savers receive. This is not only a temporary disequilibrium effect but one which persists in steady-state equilibrium. Unlike earlier papers by Feldstein and by Green and Sheshinski, the current study recognizes that firms finance investment by both debt and equity in a ratio that depends on the tax rates and on the rate of inflation.

The recent high rates of inflation have drawn professional and public attention to the undesirable ways in which inflation affects the functioning of our tax system. ${ }^{1}$ The most widely perceived problem is that the progressive structure of the personal income tax causes effective tax rates to increase arbitrarily when inflation raises nominal incomes. Several economists (Friedman 1974; Bailey 1975; Fellner et al. 1975) have suggested that the tax rates should be redefined as functions of real income by indexing to consumer prices all of the dollar amounts in the tax law, for example, personal exemptions and the limits of the rate brackets.

* We are grateful to the National Science Foundation for financial support under grants SOC75-14656, SOC71-03803, and SOC74-11446. We have benefited from comments on a previous draft by Alan Auerbach, who pointed out an error in our treatment of historic cost appreciation; the correct results derived by Auerbach are presented in the Appendix, of which he is the author.

1 See Brinner (1973), Friedman (1974), Diamond (1975), Fellner, Clarkson, and Moore (1975), Aaron (1976), Feldstein (1976), and Green and Sheshinski (1977). 
There is a second and more severe problem that has received less attention. Because we currently tax the nominal income from investment (nominal interest and nominal capital gains) and allow borrowers to deduct nominal interest costs, the real net of tax returns to debt and equity will be altered by a change in the rate of inflation. This occurs even if the tax is not progressive. This paper shows that, with the current U.S. tax laws, even moderate rates of inflation can cause very substantial changes in net real yields.

An unanticipated change in the rate of inflation would of course benefit debtors and harm creditors. In order to abstract from such temporary effects and from the problems of the transition from one equilibrium to another, this paper focuses only on the comparative steady-state equilibria of a growing economy with different rates of inflation.

In earlier papers, Feldstein (1976) and Green and Sheshinski (1977) examined the effects of inflation on the real net rate of interest in an economy in which all investment is financed by debt. In contrast, in this study firms finance investment by issuing both debt and equity. Because the interest rate and the equity yield that a firm must pay are increasing functions of the firm's debt-equity ratio, the firm can choose an optimal debt-equity ratio that minimizes its total cost of capital. The debtequity ratio depends on the tax rates and on the rate of inflation.

The first section of this paper presents a model of the growing economy and of the firm's financial behavior. Section II derives the comparative steady-state dynamics and investigates the effects of inflation on the debtequity ratio and the real net yields to debt and equity. Section III discusses the nature of complete adjustment of the tax law to neutralize the effect of inflation and the effect of partial adjustment. A brief concluding section then discusses the implications of inflation in a more general model than the one that is fully analyzed here.

\section{The Model}

We study the problems discussed above by uniting a simple variant of a full-employment monetary-growth model, with a system describing the supply of capital to firms individually and collectively. The risks inherent in the ownership of financial assets will be determinants of the supply of capital to firms in the form of equity or debt obligations along with their respective rates of return.

The economy is thereby described at both the level of the aggregate and the individual firm. The assumption that all firms have the same constant returns-to-scale technology will serve to link these two levels via symmetry conditions in the equilibrium. We will be considering steadystate growth equilibria throughout this paper. 


\section{The Aggregative Structure}

We consider a neoclassical one-commodity growth model. The labor force $L$ is assumed to grow exogenously at rate $n$. Since firms are identical and have constant returns-to-scale technologies, aggregate output $Y$ is also given by the same production function

$$
Y=F(K, L),
$$

where $K$ is the level of the aggregate capital stock. We will write this in its usual per capita form as

$$
y=f(k),
$$

where $y=Y / L$ and $k=K / L$. Money does not enter the production function directly. It is, however, held as an asset by individuals. The equation

$$
m=\mathscr{L} k
$$

describes the desired level of real money balances per capita, $m$, as a multiple of the real capital stock. This multiple, $\mathscr{L}$, may be a function of the relative rates of return to holding these assets. Either of these net returns may depend on the rate of inflation or the tax system. However, as Feldstein (1976) has pointed out, the magnitude of the real effects of inflation induced through shifts in $m / k$ is very small. We will therefore treat $\mathscr{L}$ as a constant for most of our analysis. Money balances are held by individuals directly, rather than by firms; this simple but somewhat unrealistic assumption is traditional in the monetary-growth literature. ${ }^{2}$

The government is assumed to have a desired level of expenditures equal to a fraction, $\gamma$, of national income. Its revenue sources are threefold: various corporate, interest-income, and capital gains taxes to be described below; the issuance of money; and a labor-income tax. When we compare steady states attainable through different rates of inflation, the labor-income tax will be assumed to vary so as to maintain the government's budget-balance condition. Even if labor is supplied elastically, this tax will affect the real variables of the system only insofar as it changes savings and ultimately the capital stock (Feldstein 1974).

Since the real level of money balances is $m$, and the labor force is growing at rate $n$, which will therefore be the growth rate of output and capital in the steady state, the government can issue money at the rate of $m n$ without causing any inflation in the price level. Inflation at rate $\pi$ produces extra revenue of $\pi m$.

Disposable income per capita, $d$, is therefore given by the national

2 Green and Sheshinski (1977) have studied a system in which firms hold money for production purposes. The comparative statistics are similar to the traditional case. 
income per capita, $y$, minus total taxes and the real capital losses induced by inflation, $\pi m$. Total taxes are just $\gamma y$ minus the part of government spending financed through the issuance of money $(\pi+n) m$. Thus,

$$
d=(1-\gamma) y+m n \text {. }
$$

Savings are a proportion, $\sigma$, of disposable income. The number $\sigma$ will depend, in general, on the real net rate of return to be earned on the assets that can be held by individuals, as well as their riskiness. In this way, the tax system and the rate of inflation will influence savings and hence the steady-state behavior of the model. This is the effect emphasized by Feldstein (1976).

In this paper we will be concentrating on the form in which saving is done and on the interplay between this, the tax structure, and corporate financial behavior. For simplicity, therefore, it is assumed that $\sigma$ is a constant.

Savings, $\sigma d$, is divided between capital and real money balances according to (3). The steady-state equation is therefore

$$
\sigma d=n(1+\mathscr{L}) k
$$

expressing the equality between actual savings and that necessary to keep the real variables growing at the same rate as population. Because of the specification of the government budget equation that we have employed, $d$ depends only on $k$, as can be seen directly in (4). Therefore, (5) determines the unique steady-state level of the aggregative variables independent of the government's monetary or tax policy. We will therefore take $k, y$, and $m$ as predetermined in our analysis below.

\section{The Disaggregated Structure: Corporate Financial Policy and the Supply of Capital}

Both the supply and demand sides of the market for corporate financial obligations are intimately connected with the tax structure and with the rate of inflation. There are four basic features of the tax structure that we will be considering below: (1) A corporate income tax at rate $\tau$, for which the base is corporate income net of interest payments on debt and net of depreciation based on historic costs. (2) A personal capital income $\operatorname{tax}$ at rate $\theta$, which is the same for interest on debt and for equity income; this equity income consists of both dividends and retained earnings, including the inflation-induced real gain that holders of equity receive because of the fall in the real value of debt claims on the firm's assets. ${ }^{3}$

${ }^{3}$ In an earlier version of this paper, we assumed that the personal tax rate on interest income was higher than the rate on equity income because of the relatively favorable treatment of retained earnings. Subsequent work has shown us that the problem is more complex because the ratio of dividends to retained earnings varies with the rate of inflation. We therefore ignore the distinction between dividends and retained earnings until we can provide a more complete analysis. 
(3) The cost of depreciation is deductible from corporate income at the historic nominal value of the capital rather than at replacement cost. This induces an extra tax proportional to the rate of inflation, whose effective rate we denote by $\delta$.

Let us first consider the decision to be made by firms. Since we have assumed that all firms have identical production functions, we study the behavior of a representative producer whose financial goal is to minimize the cost of financing a unit of capital. His only decision is the mixture of debt and equity to use. Let $b=$ proportion of capital financed by debt; $e=$ dividends paid by firms plus retained earnings, per unit of equity; $i=$ gross interest cost to firm, per unit of debt obligation. The real cost of capital to the firm is computed as follows: Since the interest costs are deductible from profits for computing taxable corporate income, the net interest cost of debt is only $(1-\tau) i$. Moreover, the real value of the debt is falling at the rate of inflation, since the principle is denominated in nominal terms. Therefore, the real net cost of debt finance is $(1-\tau) i$ $-\pi$. Equity finance, however, simply costs $e$, as the value of the equityholders claim on real capital rises with the rate of inflation. Therefore, a unit of capital financed by $b$ units of debt and $(1-b)$ units of equity has a real net cost of

$$
N=b(1-\tau) i+(1-b) e-b \pi .
$$

We assume that the firm perceives the effect of its choice of $b$ on the net rates of return it must provide to its two classes of investors and hence on the cost it must incur for this financing. In a model in which the securities of all corporations were perfect substitutes, $e$ and $i$ would have an infinite elasticity with respect to $b$. Here we will be implicitly supposing that there are few enough risk classes of firms so that $e$ and $i$ have nonzero derivatives with respect to $b$. The supply-of-funds schedule faced by an individual firm depends also on the riskiness and returns from other assets. In this model, due to symmetry conditions, we can use the market's debt-equity ratio and promised yields on the two classes of assets.

We indicate variables relevant to the rest of the market, treated as parameters by the individual firm, by the symbol ^. Thus we denote

$\hat{\ell}_{N}=$ real net rate of return promised on equity holdings by the "market,"

$\hat{i}_{N}=$ real net rate of return promised on debt holdings by the "market,"

$\hat{b}=$ proportion of capital in the "market" financed by debt,

$e_{N}=$ real net rate of return on holdings of equity in the representative firm,

$i_{N}=$ real net rate of return on holdings of debt issued by the representative firm. 
The supply of investment funds to the firm can then be written through the inverse supply function as:

$$
\begin{aligned}
& e_{N}=\phi\left(b, \hat{b}, \hat{e}_{N}, \hat{i}_{N}\right), \\
& i_{N}=\Psi\left(b, \hat{b}, \hat{e}_{N}, \hat{\imath}_{N}\right) .
\end{aligned}
$$

To determine the net return to the holders of equity after inflation and taxation, it is necessary to describe the financial and accounting rules used by the tax authorities. The real earnings of equity per dollar of equity capital, after corporate taxes and payments of the other factors have been deducted from sales revenue, is $e$. In the absence of inflation, the net return to the equity owners per unit of equity capital is $(1-\theta) e$, where $\theta$ is the personal tax rate on capital income. Inflation raises the nominal value of the firm's capital stock at rate $\pi$. Since the value of the debt is fixed in nominal terms, all of this increase in the nominal value of the firm's capital accrues to holders of equity. These nominal capital gains are taxed at the capital gains tax rate, $c$. Thus the net yield per unit time on a unit of equity is ${ }^{4}$

$$
e_{N}=(1-\theta) e-c \pi .
$$

This implies directly that

$$
e=\frac{e_{N}}{1-\hat{\theta}}+\frac{c \pi}{1-\theta} .
$$

The case of the holders of debt is somewhat simpler. They are taxed at a rate $\theta$ on their nominal return and experience inflation-produced capital losses at rate $\pi$ which are uncompensated by the tax system. Therefore,

$$
i_{n}=(1-\theta) i-\pi,
$$

and

$$
i=\frac{i_{N}+\pi}{1-\theta}
$$

4 The situation would be more complex if dividends and retained earnings were taxed differently. Consider an increase in the rate of inflation. This means that the debt-equity ratio would tend to fall continuously since the nominal value of equity is rising. To offset this tendency and maintain a stable value of $b$ (which may, of course, differ from the $b$ chosen before the change in $\pi$ ), the firm must issue new debt and pay out the proceeds as dividends: Note that it cannot retain these proceeds because doing so would cause the firm to depart from its equilibrium growth rate. This process of converting these real gains (that result from the inflation-induced fall in the value of existing debt) from retained earnings to dividends has no tax consequence if dividends and retained earnings are taxed equally. The process is therefore ignored in equation (9). In a more realistic model, in which dividends are taxed more heavily than retained earnings, inflation would raise the effective tax rate by causing more of the real return to have the apparent form of dividends rather than retained earnings. 
In minimizing (6) with respect to $b$, the firm uses (10) and (12) together with the specification of the supply functions given in (7) and (8). This minimization is carried out in the next section, which is concerned with the long-run comparative statics of the model.

A second equilibrium condition for the system is that the firms promised payments can be exactly met by their net profits. One can either view this as a type of zero-profit condition arising because the firms are numerous, or a cash-flow balance condition for feasibility and equilibrium within the firm.

Since the labor market is competitive, the real gross rate of profit is equal to the marginal product of capital, $f^{\prime}$. This is taxed at a rate $\tau$. Nominal income of the firm includes this plus the inflation-produced gain on the capital stock which is $\pi$. Moreover, since the real value of the debt has fallen at the rate $\pi$, the firm can borrow $b \pi$ continually without changing its debt-equity ratio. Therefore, the sources of funds amount to

$$
(1-\tau) f^{\prime}+\pi+b \pi \text {. }
$$

The uses of funds are composed of the direct capital costs (which are being minimized as discussed above) of $b(1-\tau) i+(1-b) e$, the increased nominal value of the equity $\pi$, and a tax allowance for depreciation.

Ordinarily we can regard depreciation of the capital stock as being included in the definition of the production function. But in a world with both taxes and inflation, depreciation allowances at historic cost underestimate the necessary capital requirements. We suppose, therefore, that the additional funds used up by the difference between real depreciation and the historic cost allowance by the tax system are $\delta \pi$. The parameter $\delta$ reflects the timing and the rate of depreciation. (An example of the calculation of $\delta$ will be presented in the Appendix.) The total uses of funds are, therefore,

$$
b(1-\tau) i+(1-b) e+\pi+\delta \pi .
$$

Equating (13) and (14) we have the condition

$$
(1-\tau) f^{\prime}=b(1-\tau) i+(1-b) e+(\delta-b) \pi,
$$

describing the cash flow of the representative firm in equilibrium.

In equilibrium, firms must be choosing identical financing mixes and rates of return on the two assets. Thus,

are equilibrium conditions.

$$
\begin{aligned}
b & =\hat{b}, \\
e_{N} & =\hat{e}_{N}, \\
i_{N} & =\hat{i}_{N}
\end{aligned}
$$

Finally, recall that the supply of savings to the entire sector is fixed, being a constant fraction of disposable income. The mixture of debt and 
equity assets acceptable to the market depends on the net rates of return that the market provides. Specifically, we assume that the differences in the net real rates of return are the determining variables,

$$
\hat{b}=\eta\left(\hat{\imath}_{N}-\hat{e}_{N}\right)
$$

and that $\eta^{\prime}>0$, reflecting the fact that higher returns on bonds make them relatively more attractive in the aggregate portfolio.

In summary, therefore, the level of capital per head is fixed by (5) and will be treated as constant throughout our analysis. The remaining six variables, $b, \hat{b}, e_{N}, \hat{e}_{N}, i_{N}, \hat{i}_{N}$, are determined through the system of equations given by the conditions for a minimum of (6) and by (15)-(17). The remaining variables $e$ and $i$ can be recomputed from (10) and (12), respectively.

\section{Effects of Changes in Inflation}

We are now ready to study how a permanent change in the rate of inflation changes the steady-state equilibrium of the economy. In general, an increase in the rate of inflation will change the capital intensity of the economy and, for any capital intensity, will change the debt-equity ratio and the real net yields on debt and equity. In order to focus on the effects that do not depend on the change in capital intensity, we are examining the special case in which inflation does not alter the capital labor ratio; we return in Section IV to consider the effect of inflation on capital intensity.

We are therefore considering an economy in which the ratio of saving to disposable income $(\sigma)$ and the ratio of money to capital $(L)$ are constant. Equation (5) then implies a unique capital labor ratio that is independent of the rate of inflation. Although the assumption of inelastic saving and liquidity preference thus makes the economy decomposable, this is not quite the classical dichotomy between real and nominal quantities. The first part of the model can be solved for an equilibrium capital intensity and the corresponding real national income and marginal products of labor and capital. Conditional on this marginal product of capital, the second part of the model finds the equilibrium debt equity and the real after-tax yields on debt and equity. It is this part that we now examine.

Equation (15) showed that the firm's after-tax income $\left[(1-\tau) f^{\prime}\right.$ $-\sigma \pi+b \pi]$ is divided between net interest payments $[b(1-\tau) i]$ and a return to equity $[(1-b) e]$ :

$$
(1-\tau) f^{\prime}-\delta \pi+b \pi=b(1-\tau) i+(1-b) e .
$$


Using (10) and (12), we can rewrite the cash-flow equation (18) as

$$
\begin{aligned}
(1-\tau) f^{\prime} & =\frac{b(1-\tau) i_{N}}{1-\theta}+\frac{(1-b) e_{N}}{1-\theta} \\
& +\pi\left[\frac{b(\theta-\tau)}{1-\theta}+c \frac{(1-b)}{1-\theta}+\delta\right] .
\end{aligned}
$$

Multiplying (19) by $(1-\theta)$ we have

$$
\begin{aligned}
(1-\theta)(1-\tau) f^{\prime} & =b(1-\tau) i_{N}+(1-b) e_{N} \\
& +\pi[b(\theta-\tau)+c(1-b)+\delta(1-\theta)] .
\end{aligned}
$$

This is the first of the three basic equations to be solved for $b, e_{N}$, and $i_{N}$.

The net cost of capital to the firms $(N)$ was shown in equation (6) to be $b(1-\tau) i+(1-b) e-b \pi$. Substituting again for $i$ and $e$ yields

$$
(1-\theta) N=b(1-\tau) i_{N}+(1-b) e_{N}+\pi[(\theta-\tau) b+(1-b) c] .
$$

The firm selects $b$ to minimize this cost, implying

$$
(1-\tau) i_{N}-e_{N}+\pi(\theta-\tau-c)+b(1-\tau) \Psi_{1}+(1-b) \phi_{1}=0 \text {, }
$$

where $\Psi_{1}=\partial i_{N} / \partial b$ and $\phi_{1}=\partial e_{N} / \partial b$ along the firm's financial supply equations (7) and (8).

The final equation is the market's demand for debt relative to all capital. Equation (17) and the equilibrium condition $b=b, i_{N}=\hat{i}_{N}$, and $e_{N}=\hat{e}_{N}$ imply

$$
b=\eta\left(i_{N}-e_{N}\right)
$$

Totally differentiating equations (20), (22), and (23) with respect to $b, e_{N}, i_{N}$, and the predetermined $\pi$ yields:

$$
\begin{aligned}
& {\left[\begin{array}{ccc}
Q & (1-b) & b(1-\tau) \\
Z & -1 & (1-\tau) \\
1 & \eta^{\prime} & -\eta^{\prime}
\end{array}\right]\left(\begin{array}{l}
d b \\
d e_{N} \\
d i_{N}
\end{array}\right)} \\
& \quad=-\left[\begin{array}{c}
b(\theta-\tau)+(1-b) c+\delta(1-\theta) \\
\theta-\tau-c \\
0
\end{array}\right] d \pi,
\end{aligned}
$$

where $Q=(1-\tau) i_{N}-e_{N}+\pi(\theta-\tau-c)$, and $Z=\partial^{2}(1-\theta) N / \theta b^{2}$. Since both $i_{N}$ and $e_{N}$ are increasing functions of $b\left(\Psi_{1}>0\right.$ and $\left.\Phi_{1}>0\right)$, equation (5) implies $Q<0$. The second-order condition for choosing $b$ to minimize the cost of capital implies $Z>0$. 


\section{The Debt-Equity Ratio}

Solving (24) for $d b / d \pi$ we have:

$$
\frac{d b}{d \pi}=\frac{\eta^{\prime}[(\tau-\theta)+c(1-\tau)-\tau \delta(1-\theta)]}{\Delta},
$$

where $\Delta$ is the determinant of the matrix on the left-hand side of (24). We have that $\Delta=(1-\tau)+\eta^{\prime}[\tau Q+Z(1-b \tau)]$. Clearly, $\Delta>0$ when $\eta^{\prime}=0$; although the sign of $\Delta$ is ambiguous when $\eta^{\prime}>0$ (because $Q$ and $Z$ are of opposite sign), we will continue to assume throughout this paper that $\Delta>0$ even when we consider $\eta^{\prime}>0$.

When $c$ and $\delta$ are both zero, so that economic depreciation is allowed and the taxation of capital gains has been adjusted for inflation, we see that $d b / d \pi$ has the sign of $\tau-\theta$.

It is important to note that the parameter values $c=\delta=0$ do not correspond to a full indexing of the tax system, in the sense of making it inflation proof. There are two reasons for this, which we will explore in detail in Section IV. First, it is still nominal interestcost and not the real costs that is deductible from profits of firms for tax purposes. Second, nominal interest income, rather than real interest, is taxed at the individual level. Thus, although the purely inflationary gains of equity holders are not taxed when $c=0$, bond holders are not treated symmetrically. (Under a full indexing of the tax system, we would have $i_{N}=[1-\theta][i-\pi]$, and not $[1-\theta] i-\pi$.)

These two distortions account for the nonneutrality of inflation with respect to the debt-equity ratio as derived above.

The sign of the numerator of (25) cannot be determined on purely theoretical grounds. However, for values of the tax parameters corresponding roughly to the current U.S. tax laws ( $\tau=.45$ and $\theta=.30$ ), we can see that $d b / d \pi$ would be positive even if $c=0$ and $\delta=.3$, which are, as we will see, lower and upper bounds on the values of these parameters, respectively.

\section{The Real Net Rate of Interest}

The effect of inflation on the real rate of interest has been the subject of theoretical and empirical research at least since Irving Fisher (1930). Equation (26) shows that the real net rate of interest is unlikely to remain unchanged with our tax system:

$$
\frac{d i_{N}}{d \pi}=\frac{\begin{array}{c}
(\tau-\theta)-\delta(1-\theta)+\eta^{\prime}\{Q(\theta-\tau-c)-Z[b(\theta-\tau) \\
+(1-b) c+\delta(1-\theta)]\}
\end{array}}{\Delta} .
$$

Consider first the case in which $c=\delta=0$. The real net yield now increases if $\tau>\theta$ and decreases if $\tau<\theta$. With $\tau>\theta, i_{N}$ rises for two 
reasons. With a fixed debt-equity ratio, the firm can increase the nominal rate of interest by $\pi /(1-\tau)$ and keep the same real net rate of interest. This raises the net nominal yield to households by $(1-\theta) \pi /(1-\tau)$ and the real net yield by $(1-\theta) \pi /(1-\tau)-\pi=\pi(\tau-\theta) /(1-\tau)$. In addition, with $\tau-\theta>0$, inflation induces firms to substitute debt for equity, thus raising the interest rate further by a risk premium. Positive taxation of nominal capital gains and historic cost depreciation reduce the overall net profits of the firm available for interest payments.

In a previous study, Feldstein (1976) found that in an all debt-financed economy with economic depreciation $(\delta=0$ and $c=0)$, the real net rate of interest would remain unchanged only if $\tau=\theta$. Equation (27) shows that this continues to be true when the firms choose an optimal mix of debt and equity finance.

The magnitude of the change in $i_{N}$ can be crudely approximated by assuming $\eta^{\prime}=0$, that is, ignoring the shift in the debt-equity ratio. Equation (26) then implies

$$
\frac{d i_{N}}{d \pi}=\frac{\tau-\theta-\delta(1-\theta)}{1-\tau} .
$$

It is of interest to note first that this expression is independent of $c$, the inflation-induced taxation of equity earnings. As noted above, $d i_{N} / d \pi$ is positive when $\tau>\theta$ if $\delta=0$. However, for tax rates close to those currently in force in the United States, even modest values of $\delta$ may completely offset this positive effect. If $\delta=.2$, the real net yield on debt would be approximately insulated from inflation, but only as the consequence of two equal and opposite forces.

Intuitively, historic cost depreciation causes an implicit taxation of the firm's cash flow which increases with the rate of inflation. Part of this is borne by equity and part by debt. But, at the same time, the deductibility of nominal interest costs is making debt a cheaper source of finance for firms, on the margin. Firms attempt to issue more debt in order to take advantage of this effect, but in the aggregate the market is not willing to absorb any more debt, since $\eta^{\prime}=0$. Therefore, the gross interest costs, $i$, get bid up because the shift in the supply curve for bonds decreases their price. Although some of this increase is taxed at the personal level and some further losses are caused by the increased inflation itself, the net return to holders of debt would be increased for a given level of gross profits. Because corporate and personal tax rates are close in magnitude, the historic cost-depreciation effect is important and may actually change the direction that would be predicted by analyzing the capital markets in isolation.

Note, moreover, that the effect of inflation on $i_{N}$ will vary among individual investors in a way that depends on their own personal tax rates. Bondholders with low values of $\theta$ will benefit from inflation, while 
those with high tax rates will receive a lower net interest rate as inflation rises. Equation (19) implies that an individual with a 50 percent marginal rate $(\theta=.5)$ will find that even a moderate rate of inflation eliminates his real interest income. To see this, note that in the late 1950s and early 1960s when there was no inflation, the interest rate was $i=.04$, and therefore for a 50 percent marginal rate individual, $i_{N}=(1-\theta) i=$ .02. The Appendix shows that $\delta=.20$ is a reasonable value for U.S. conditions. With $\tau=.45$, equation (27) implies $d i_{N} / d \pi=-.27$. Thus, an inflation rate of $\pi=.08$ would eliminate all of the real net interest because of the way in which the tax law operates.

$$
\begin{aligned}
& \text { Since } i=\left(i_{N}+\pi\right) /(1-\theta), \\
& \quad \frac{d i}{d \pi}=\frac{1}{1-\theta} \frac{d i_{N}}{d \pi}+1=\frac{1-\delta}{1-\tau} .
\end{aligned}
$$

With the value of $\delta=.20$ derived in the Appendix, equation (28) implies $d i / d \pi=1.45 .^{5}$

\section{The Net Real Return on Equity}

The response of the real after-tax return of equity owners is, from equation (24),

$$
\frac{d e_{N}}{d \pi}=\frac{\begin{array}{c}
-(1-\tau)[c+\delta(1-\theta)]+\eta^{\prime}\{Q(\theta-\tau-c) \\
-2[b(\theta-\tau)+(1-b) c+(1-\delta) \theta]\}
\end{array}}{\Delta} .
$$

It is again useful to begin with the case $\delta=c=0$ :

$$
\frac{d e_{N}}{d \pi}=(\tau-\theta) \eta^{\prime}(b Z-Q) / \Delta=(b Z-Q) \frac{d b}{d \pi} .
$$

Since $Z>0$ and $Q<0,{ }^{6}$ the sign of $d e_{N} / d \pi$ is the same as the sign of $d b / d \pi$. In this case, the yield on equity increases because the debt-equity ratio rises, increasing the riskiness of equity. If inflation decreases the real value of depreciation $(\delta>0)$ or if nominal capital gains are taxed $(c>0)$, the return to equity owners is thereby reduced.

5 The empirical evidence indicates that a sustained change in the inflation rate leads after a few years to an approximately equal change in the nominal interest rate; see Yohe and Karnovsky (1969), Feldstein and Eckstein (1970), and Feldstein and Chamberlain (1973). Feldstein's (1976) model, which ignored both depreciation and equity finance, implied that the nominal interest rate should rise by twice the change in the rate of inflation; this contradiction with the evidence is substantially resolved by the current and more satisfactory model. The calculation of $\delta$ in the Appendix ignores the accelerated depreciation features in the actual tax laws. The empirical analyses also failed to incorporate taxation explicitly and may provide biased estimates of the effects of inflation on interest rates.

6 See the discussion following equation (24). 
A rough approximation of the magnitude of the change in the yield on equities can be obtained by ignoring the change in the debt-equity ratio, that is, by setting $\eta^{\prime}=0:^{7}$

$$
\frac{d e_{N}}{d \pi}=-[c+\delta(1-\theta)]
$$

The statutory rate of tax on capital gains is approximately one-half of the individual rate on ordinary income. In addition, the effective rate is reduced by the rule delaying the tax liability until the gain is realized. It may be reasonable to estimate $c=.2 \theta .{ }^{8}$ With the estimate that $\delta=.2$, equation (31) implies $d e_{N} / d \pi=-.2$ for all values of $\theta$. A 10 percent rate of inflation reduces the real net return to equity by 2 percentage points.

What is the corresponding value of $e_{N}$ when $\pi$ is zero? Equation (18) implies

$$
e=(1-\tau)\left(f^{\prime}-b i\right) /(1-b),
$$

and, since $e_{N}=(1-\theta) e$ when $\pi=0$,

$$
e_{N}=(1-\theta)(1-\tau)\left(f^{\prime}-b i\right) /(1-b) \text {. }
$$

Using the values of $i=.04$ and $b=.3$ to represent conditions when the inflation rate was zero and $f^{\prime}=.12$ as the pretax marginal product of capital (Feldstein and Summers 1977), equation (33) implies $e_{N}=.85$ $(1-\theta)$. An investor with a marginal tax rate of $\theta=.3$ receives $e_{N}=$ .059 ; a 10 percent rate of inflation cuts the real net return to equity by about one-third. With $\theta=.5, e_{N}=.042$ when there is no inflation and a 10 percent rate of inflation cuts the real net return to equity in half.

\section{Adjusting Taxes for Inflation}

It is a very undesirable feature of our tax system that the equilibrium real net rates of return on debt and equity vary with the rate of inflation. This section considers how the definitions of taxable income and expenses can be varied to eliminate the effect of inflation on equilibrium real yields.

The most obvious adjustments to the tax law are to end the taxation of nominal capital gains $(c=0)^{9}$ and to allow replacement cost depreciation of capital assets $(\delta=0) .{ }^{10}$ Two further changes should be made,

${ }^{7}$ With $\eta^{\prime} \neq 0$, part of the increase in $e_{N}$ reflects an increase in risk. That ambiguity is avoided by assuming $\eta^{\prime}=0$.

See Bailey (1969) for estimates of the effect of the deferral of taxation on the effective rate of capital gains tax.

${ }^{9}$ Specific proposals to adjust the capital gains tax in this way have been made by Brinner (1973) and Diamond (1975).

10 See Fellner et al. (1975) for a discussion of this subject. 
both in the tax treatment of interest. First, individuals should be taxed on their real interest receipts, $b(i-\pi)$. Second, firms should be permitted to deduct only their real interest expense in calculating their taxable profits; that is, taxable profits per unit of capital are $f^{\prime}-b(i-\pi)$, so that the company tax is $\tau\left[f^{\prime}-b(1-\pi)\right]$. Note that this is equivalent to allowing a deduction of the nominal interest payment and taxing the real gain that results from the decline in the real value of the debt: $\tau\left(f^{\prime}-b i\right)+\tau b \pi$.

With these changes, the firm's nominal after-tax income $\left[(1-\tau) f^{\prime}\right.$ $+b \pi]$ is divided between net interest payments $[b i-\tau b(i-\pi)]$ and a return to equity $[(1-b) e]:{ }^{11}$

$$
(1-\tau) f^{\prime}=b \pi=b i-\tau b(i-\pi)+(1-b) e .
$$

With this change, $i_{N}=(1-\theta)(i-\pi)$, or $i=\pi+i_{N} /(1-\theta)$. Similarly, equation (9) becomes $e_{N}=(1-\theta) e$, or $e=e_{N} /(1-\theta)$. Substituting into (34) and rearranging yields

$$
(1-\tau) f^{\prime}=\frac{(1-\tau) b i_{N}}{1-\theta}+\frac{(1-b) e_{N}}{1-\theta} .
$$

This equilibrium condition (which is analogous to [19] without indexing) is now completely independent of the rate of inflation.

Since the net cost of capital to the firm is the right-hand side of (35), the condition for choosing $b$ to minimize the cost of capital is also independent of $\pi$ :

$$
(1-\tau) i_{N}-e_{N}+b(1-\tau) \psi_{1}+(1-b) \phi_{1}=0 .
$$

The third equation, the market demand for bonds, is always defined in terms of real net yields :

$$
b=\eta\left(i_{N}-e_{N}\right) .
$$

Thus the three equations that determine the equilibrium values of $b$, $i_{N}$, and $e_{N}$ are independent of the rate of inflation. The tax changes described above are sufficient to eliminate completely the arbitrary effects of inflation.

At the current time, most discussions of adjusting the tax law for inflation have stopped short of the complete indexing that has just been described. The most common proposals call for replacement cost depreciation and taxing only real capital gains. This partial indexing corresponds to the special case of $\delta=c=0$ that was examined in Section II. The effect of the different approaches to indexing in comparison to the current tax rules can be seen in table 1 for individuals at three different marginal tax rates. Note that replacement cost depreciation only $(\delta=0$, indexing

1 Note that this is analogous to equation (18) without indexing. 
TABLE 1

Equilibrium Real Net Rates of Return under Various Tax Rules

\begin{tabular}{|c|c|c|c|c|c|c|}
\hline \multirow{3}{*}{$\begin{array}{c}\text { Personal } \\
\text { Tax Rate } \\
(\theta) \\
\text { AND } \\
\text { Net Real } \\
\text { Return }\end{array}$} & \multirow{3}{*}{$\begin{array}{c}\text { No } \\
\text { INFLATION }\end{array}$} & \multicolumn{5}{|c|}{10 Percent Rate of Inflation } \\
\hline & & \multirow{2}{*}{$\begin{array}{c}\text { Current } \\
\text { Rule }\end{array}$} & \multicolumn{3}{|c|}{$\begin{array}{l}\text { Partial Indexing } \\
\text { Rules* }\end{array}$} & \multirow{2}{*}{$\begin{array}{l}\text { Complete } \\
\text { Indexing }\end{array}$} \\
\hline & & & 1 & 2 & 3 & \\
\hline \multicolumn{7}{|l|}{$\theta=.50$} \\
\hline$e_{N} \ldots \ldots \ldots \ldots$ & .042 & .022 & .032 & .042 & .042 & .042 \\
\hline$\theta \stackrel{i_{N}}{=} .30: \cdots \cdots \cdots$ & .020 & -.007 & .011 & .011 & .061 & .020 \\
\hline$e_{N} \ldots \ldots \ldots \ldots$ & .059 & .039 & .053 & .059 & .059 & .059 \\
\hline$\theta \stackrel{i_{N}}{=} .0: \cdots \cdots \cdots$ & .028 & .030 & .055 & .055 & .085 & .028 \\
\hline$e_{N} \ldots \ldots \ldots \ldots$ & .085 & .065 & .085 & .085 & .085 & .085 \\
\hline$i_{N} \ldots \ldots \ldots \ldots$ & .040 & .084 & .122 & .122 & .122 & .040 \\
\hline
\end{tabular}

Note. - The calculations are based on the following assumptions: $f^{\prime}=.12, \eta^{\prime}=0, b=.3, \tau=.45$, $c=.2 \theta$, and $\imath=.04$ at $\pi=0$. See text for details of equilibrium relationships.

- Partial indexing rules: (1) replacement cost depreciation $(\delta=0)$; (2) replacement cost depreciation $(\delta=0)$, no taxation of nominal capital gains $(c=0)$; $(3)$ replacement costs depreciation $(\delta=0)$, no taxation of nomual capital gains $(c=0)$, personal taxation of real interest only $[i N=(1-\theta)(i-\pi)]$.

rule 1) still causes $e_{N}$ to fall with inflation, while $\delta=0$, and $c=0$ (rule 2) makes $e_{N}$ independent of inflation. Any of the partial rules makes $i_{N}$ sensitive to inflation with the direction of the change depending on the level of $\delta$.

\section{Conclusion}

Our tax system was designed for an economy with little or no inflation. In this paper we have shown that the rates of inflation that can be expected in the future will cause capricious and undesirable changes in the effective rates of tax on capital income. This would be true even with a proportional tax, but a progressive structure can exacerbate distortions.

The inflation-induced change in the effective rate of tax implies a corresponding change in the real net rate of return on capital that savers receive. This is not only a temporary disequilibrium effect but one which persists in steady-state equilibrium.

We have purposely simplified the analysis by abstracting from the effect of inflation on portfolio composition and the potentially more important effect on the rate of saving. ${ }^{12}$ With our current tax system, inflation decreases the net rate of return and therefore is likely to decrease the rate of saving. This in turn would decrease the ratio of capital to labor and thus increase the marginal product of capital. This in turn would partially offset the fall in the after-tax rate of return, but the qualitative results of

12 See Boskin (1978) for estimates of the effect of the real net rate of return on savings. Feldstein (1976) discusses the small size of the liquidity or portfolio composition effect. 
our analysis would remain unchanged. In contrast, the partial indexing described in Section III allows for real economic depreciation for firms but does not tax the real return to savings. The likely result would be an increase in saving which would reduce the marginal product of capital, again partially reducing the effect described above but not changing the qualitative conclusions. Only complete indexing-recognizing only the real component of interest payments as well as altering the treatment of depreciation and capital gains-would make real yields and therefore saving independent of the rate of inflation.

\section{Appendix}

\section{The Effect of Inflation on the Tax Value of Depreciation}

\section{Alan Auerbach}

In this Appendix we calculate the implicit rate of tax induced by historic cost depreciation in a period of inflation, that is, the value of the parameter $\delta$ used in the text. We shall investigate the special case in which capital decays ("evaporates") exponentially.

Consider an investment of $\$ 1$ of capital at time $t=0$. With exponential depreciation at rate $d$, the net marginal product of capital $f^{\prime}$ can be written as $f^{\prime}=$ $g^{\prime}-d$, where $g^{\prime}$ is thus the gross marginal product of capital. In any future period, the firm pays a tax at rate $\tau$ on $g^{\prime}-b i-D(s)$, where $D(s)$ is the real tax depreciation allowed on a "machine" of age s. The firm's first-order condition, analogous to equation (15) is

$$
(1-\tau) g^{\prime}=(N+d)(1-\tau Z),
$$

where $Z$ is the present value of the tax depreciation as of the time that the investment is made:

$$
Z=\int_{0}^{\infty} e^{-N s} D(s) d s
$$

Note that when $D(s)$ corresponds to economic depreciation, that is, $D(s)=d e^{-d s}$, $Z=d /(N+d)$, and (38) becomes

$$
(1-\tau) g^{\prime}=(N+d)\left(1-\frac{\tau d}{N+d}\right),
$$

or

$$
(1-\tau)\left(g^{\prime}-d\right)=N
$$

This is identical with the condition of (15) when $\delta=0$, that is, when economic depreciation is allowed.

The method of historic cost depreciation that is in current use ${ }^{13}$ implies that $D(s)=d e^{-d s} e^{-\pi s}$, that is, the real value of the depreciation falls below economic depreciation by a factor that grows with time at the rate $\pi$. Thus, for historic cost depreciation we have $Z_{H}=d /(N+d+\pi)$, and (38) becomes

$$
(1-\tau) g^{\prime}=(N+d)\left(1-\frac{\tau d}{N+d+\pi}\right) \text {. }
$$

13 We ignore the special features of the investment credit and accelerated depreciation. 
This can be rewritten as

$$
(1-\tau) f^{\prime}+(1-\tau) d=N+d \frac{\tau d(N+d)}{N+d+\pi},
$$

or

$$
(1-\tau) f^{\prime}=N+\left(\frac{\tau d}{N+\pi+d}\right) \pi .
$$

Comparing (44) with (15) and using (6) shows that

$$
\delta=\frac{\tau d}{N+\pi+d} .
$$

For a machine that depreciates one-tenth per year, $d=.10$. At $\pi=0, N=$ $(1-\tau) f^{\prime}$ or approximately $N=.55(.12)=.066$. Thus at $\pi=0, \delta=.27$. At $\pi=.10$, equation (44) implies $N=.048$ and therefore $\delta=.18$. Lower values of $d$ imply smaller values of $\delta$ at each depreciation rate. For example, at $\pi=0$, a decay rate of $d=.067$ implies $\delta=.23$. In the text we used $\delta=.20$, a relatively conservative value for the inflation rates that have been observed in the United States.

\section{References}

Aaron, Henry. "Inflation and the Income Tax." A.E.R. 66, no. 2 (May 1976): 193-99.

Bailey, Martin J. "Capital Gains and Income Taxation." In The Taxation of Income from Captal, edited by Arnold C. Harberger and Martin J. Bailey. Washington: Brookings Inst., 1969.

_-_. "Inflationary Distortions and Taxes." Paper presented to the Brookings Conference on Inflation and the Income Tax System, Washington, October 1975.

Boskin, Michael. "Taxation, Saving, and the Race of Interest." J.P.E. 86, no. 2, pt. 2 (April 1978) : S3-S27.

Brinner, Roger. "Inflation. Deferral and the Neutral Taxation of Capital Gains." Nai. Tax J., vol. 26, no. 4 (1973).

Diamond, Peter A. "Inflation and the Comprehensive Tax Base." J. Public Econ., vol. 4, no. 3 (August 1975).

Feldstein, Martin. "Tax Incidence in a Growing Economy with Variable Factor Supply." Q.J.E. 88 (November 1974) : 551-73.

- . "Inflation, Taxes and the Rate of Interest: A Theoretical Analysis." A.E.R. 66, no. 5 (December 1976) : 809-20.

Feldstein, Martin, and Chamberlain, Gary. "Multimarket Expectations and the Rate of Interest." J. Money, Credit and Banking 5 (November 1973) : 873-902.

Feldstein, Martin, and Eckstein, Otto. "The Fundamental Determinants of the Interest Rate." Rev. Econ. and Statis. 52 (November 1970) : 363-75.

Feldstein, Martin, and Summers, Lawrence. "Is the Rate of Profit Falling?" Brookings Papers Econ. Activity, vol. 1 (1977).

Fellner, William; Clarkson, Kenneth W.; and Moore, John H. Correcting Taxes for Infation. Washington: American Enterprise Inst. Public Policy Res., 1975.

Fisher, Irving. The Theory of Interest. New York: Macmillan, 1930. 
Friedman, Milton. "Monetary Correction." In Essays on Inflation and Indexation. Washington: American Enterprise Inst. Public Policy Res., 1974.

Green, Jerry, and Sheshinski, Eytan. "Budget Displacement Effects of Inflationary Finance." Report no. 180, Inst. Math. Studies Soc. Sci., Stanford Univ., September 1977.

Yohe, William P., and Karnovsky, Denis S. "Interest Rates and Price Level Changes, 1952-69." Federal Reserve Bank St. Louis Rev. 51 (December 1969): 18-38. 